\title{
IMPACTS OF FEEDBACK POSTED ON GOOGLE CLASSROOM ON STUDENTS' SPEAKING SKILL
}

\author{
Vu Thi Quyen*, Nguyen Duong Ha
}

$T N U$ - School of Foreign Languages

\begin{tabular}{|c|c|c|}
\hline \multicolumn{2}{|c|}{ ARTICLE INFO } & ABSTRACT \\
\hline Received: & $03 / 3 / 2021$ & The case study aimed at investigating the influence of the teacher's \\
\hline Revised: & 29/3/2021 & feedback toward students' speaking skill on Google Classroom - a \\
\hline Published: & $31 / 3 / 2021$ & with the help of second year English maiored students at School of \\
\hline & & Foreign Languages, Thai Nguyen University. Observations and a \\
\hline \multicolumn{2}{|l|}{ KEYWORDS } & survey were applied in data collection. The study results showed that \\
\hline \multicolumn{2}{|l|}{ Giving feedback } & strengths and errors in their speeches posted on Google Classroom. \\
\hline \multicolumn{2}{|l|}{ Written feedback } & Additionally, some suggestions to deal with the errors were given. \\
\hline \multicolumn{2}{|l|}{ Google Classroom } & Therefore, thanks to the feedback, the students' speaking skill can be \\
\hline \multicolumn{2}{|l|}{ Oral performance } & $\begin{array}{l}\text { proved. Moreover, the study also finds that Google Classroom can } \\
\text { ln students save time spent on finding the teacher's comments }\end{array}$ \\
\hline \multirow{2}{*}{\multicolumn{2}{|c|}{ Homework managing }} & toward their speaking performances. The study brings other teachers \\
\hline & & $\begin{array}{l}\text { some ideas for managing students' homework in the era of technology } \\
\text { and in the Corona epidemic. }\end{array}$ \\
\hline
\end{tabular}

\section{HIỆ QUẢ CỦA NHậN XÉT TRÊN GOOGLE CLASSROOM ĐỐI VỚI KỸ NĂNG NÓI CỦA SINH VIÊN}

Vũ Thị Quyên*, Nguyễn Dương Hà

Trưòng Ngoại ngũu - ĐH Thái Nguyên

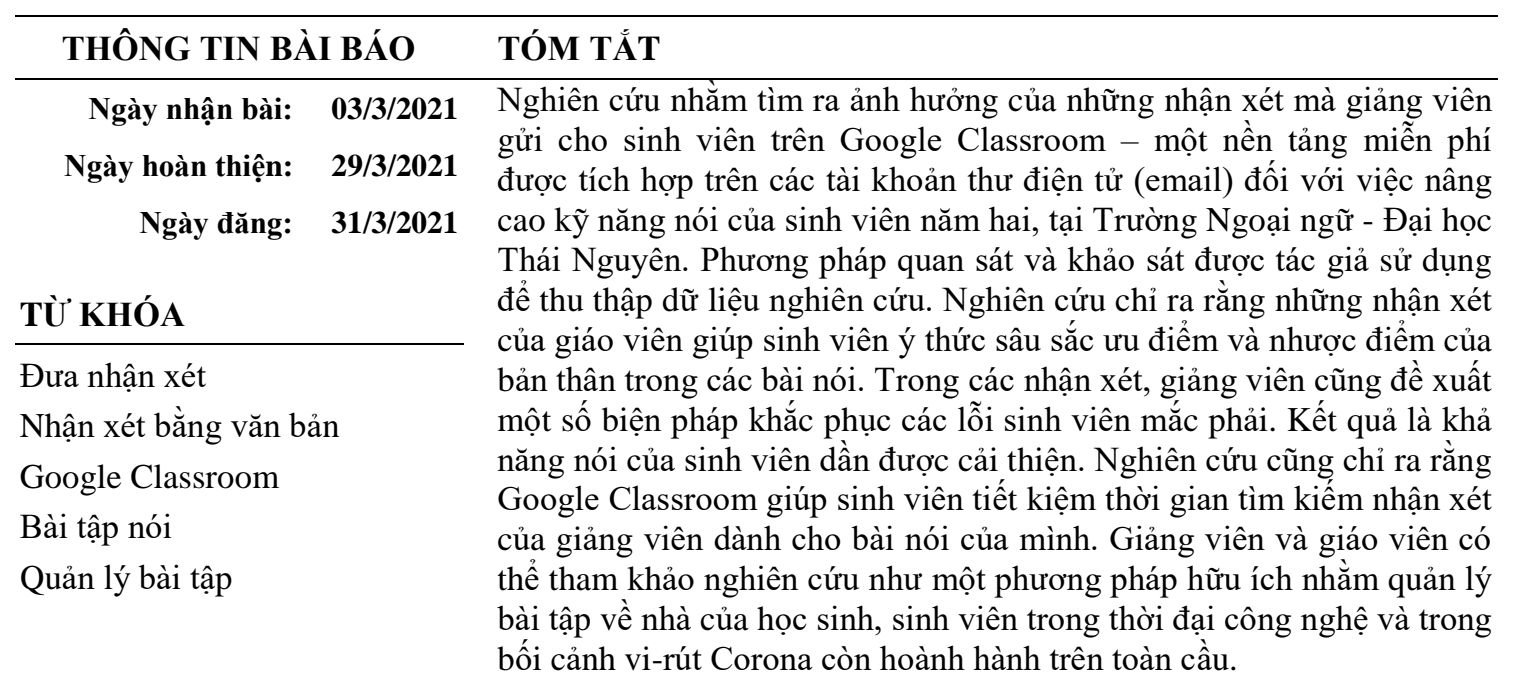

DOI: https://doi.org/10.34238/tnu-jst.4088

\footnotetext{
* Corresponding author. Email: vuquyen.sfl@tnu.edu.vn
} 


\section{Introduction}

Blended learning on social networks or platforms has been widely applied these days. In School of Foreign Languages, Thai Nguyen University; to control students' homework, teachers have been applying some free social networks namely Zalo, Facebook, Gnomio and Schoology. However, these networks and platforms have not applied systematically by all teachers at the school. In 2020, due to the COVID 19 pandemic, students had to spend nearly two months at home joining online courses with their instructors on zoom.us. They were also provided with a lot of weekly assignments on Google Classroom, which was believed most user-friendly by most of the school's lectures for some reasons. Google Classroom, which was first launched in 2014 by Gsuite, was considered as a friendly tool for all lectures and students at all levels. People who have an email account can easily access to the platform and there is a Google Classroom application for smart phones. Therefore, it is not challenging to join the classes. Additionally, Google Classroom plays a great role in making learning more easily as it is extremely useful in understandability, attractiveness, and operability [1]. Google Classroom was far better in the areas of communication, interaction, perceived usefulness, ease of use, and overall students' satisfaction [2].

After Google Classroom was chosen to manage students' homework, it was a big challenge for teachers who were supporting students to foster their speaking skill, which is considered as one of the macro skills in teaching and learning a language. Speaking skill is defined in many ways; for example, speaking is an exchange of knowledge, information, ideas, options and feeling among people [3]. Furthermore, speaking is a process in which people share information, ideas and feeling; it involves body language mannerism and style-anything that adds meaning to a message [4]. To sum up, speaking skill is a kind of communication in which utterances are produced orally with words showing the speaker's messages, knowledge, and emotion. It is the features of speaking in classroom that caused teachers' lack of confidence in using the platform for speaking activities and giving feedback toward students' performances.

It is commonly believed that if students would like to improve their speaking skill, they may need a lot of feedback toward their speaking performances. Hence, giving feedback is essential in the teaching and learning process as it helps students recognize their strengths and limitations. In language teaching, there are two types of feedback: written feedback and oral feedback. While written feedback is about the word choice and grammar rules; oral feedback is delivered orally and directly [5]. The study was carried out in speaking lessons in which teachers normally gave their feedback orally and directly to students; however, due to no onsite lessons, the researchers had no way to provide them oral and direct feedback. Hence, the feedback was typed and sent to the students.

Fiona Hylanda and Ken Hylandb [6] show that praise, criticism and suggestions should be included in the feedback. Praise is defined as an act which attributes credit to another for some characteristic, attribute, skill... which is positively valued by the person giving feedback [7]. On the other hand, criticism is defined as an expression of dissatisfaction or negative comment [8]. In this research, the teachers privately gave good points and mistakes that students had in their performances, as well as some suggestions so that the students could self-correct their errors. Due to the online lessons, the teachers could not provide the students with direct feedback; thus, they sent them some written feedback instead. This study aims at answering the question: How does the feedback on Google Classroom influence the students' speaking skill?

\section{Methodology}

This study was conducted on sixty second year English majored students whose target level was above A2, but below B1. It means that their level before the course was below or at A2. In the course, students were asked to role-play twelve situations. The VSTEP rating scale for levels 
3-5 was applied to assess the students' speaking performances on their effectiveness in using grammar, vocabulary, pronunciation, fluency and discourse analysis. After the course, all students were expected to achieve B1 level; hence, the rating skill for levels 3-5, not the one for level A2, was applied. The rating scale was carefully explained to the students at the very first lesson so that they were aware of how their speaking performances would be evaluated.

Regarding the participants' speaking ability before the study, most of the participants were thought to be at A2 level after the first year and they were about to begin their third term at the university. According the official CEFR guidelines, most of them then could:

"- Understand sentences and frequently used expressions related to areas of most immediate relevance (e.g. very basic personal and family information, shopping, local geography, employment).

- Communicate in simple and routine tasks requiring a simple and direct exchange of information on familiar and routine matters.

- Describe in simple terms aspects of his/her background, immediate environment and matters in areas of immediate need."

The textbook for the course was entitled "Life Pre-Intermediate A2-B1" by Cengage Learning. There were 15 lessons for six first units, but there were 12 lessons in which students dealt with topics and exercises in the textbook, two lessons were arranged for the progress tests and the last lesson was for the revision.

The students were asked to work in pairs, they could choose their partner on their own so that they could find team working easier and less stressed during the term. After each lesson, a topic was delivered to the students. There were two parts in a topic: a situation and some suggestions to deal with the situation. For example,

\section{Technology}

Talk to your friend and invent a new kind of robot which helps people. You should talk about the following points:

- what the robot does;

- who will use the robot;

- where people use it.

Talk with your partner/s for 2-3 minutes if you are doing the exam in pairs, or for 4-5 minutes if it is a group of three candidates. Your production will be recorded.

The pairs worked together outside the classroom, they recorded the conversations and then they posted the videos on folders which were created on their Google Classroom by the teachers.

After the due date, the teachers watched the videos, sent them some feedback toward their performances. The performances were assessed on some categories including grammar, vocabulary, fluency and discourse analysis. The feedback were sent to the students in written forms in the private comment box below their submissions. Besides showing the students what they had done well and what they should improve, the teachers also gave some suggestions so that they could self-correct their errors. There were 30 pairs of participants in this study and each of them was involved in 12 videos. Hence, there were 360 pieces of feedback delivered during the course.

To get the data for the study, observations and a questionnaire were applied. The researchers kept all the feedback in a portfolio, and then they classified their comments in three categories including praises, criticisms and suggestions so that they could find out how much the students had achieved after the videos. When the course finished, a survey which could collect data about the participants' evaluations toward the feedback was conducted. The items used for the survey were adopted from [9]. There were seven questions in questionnaire: (1) I was sent feedback regularly. (2) The feedback was detailed enough. (3) I love the privacy of the feedback. (4) It is easy to find the feedback. (5) The Google Classroom feedback was useful. (6) I appreciate feedback on Google Classroom in other courses. (7) What suggestions would be done for better 
feedback? The students were asked to put a tick on one of their option namely strongly agree, agree, neutral, disagree and strongly disagree for questions 1 to 6 . For the $7^{\text {th }}$ questions, students wrote their recommendations. The two methods were not only low-cost, easy to do but also could satisfy the aim of the research.

\section{Findings and discussion}

As being mentioned above, 360 pieces of feedback on the four categories including grammar, vocabulary, pronunciation, fluency and discourse analysis were sent to the students. In each piece of the feedback, the teachers provided their praises, criticisms and suggestions toward the students' oral performances. The number of praises, criticisms and suggestions are presented in the table 1 .

Table 1. Teachers' use of feedback acts

\begin{tabular}{ccccc}
\hline & Praises & Criticisms & Suggestions & Overall \\
\hline $1^{\text {st }}$ week Videos & $120(31.0 \%)$ & $167(43.2 \%)$ & $120(31.0 \%)$ & 387 \\
$2^{\text {nd }}$ week Videos & $123(32.4 \%)$ & $167(43.9 \%)$ & $110(28.9 \%)$ & 380 \\
$3^{\text {rd }}$ week Videos & $117(31.6 \%)$ & $157(42.4 \%)$ & $100(27.0 \%)$ & 370 \\
$4^{\text {th }}$ week Videos & $120(32.4 \%)$ & $150(40.5 \%)$ & $98(26.5 \%)$ & 370 \\
$5^{\text {th }}$ week Videos & $135(37.0 \%)$ & $147(40.3 \%)$ & $90(24.7 \%)$ & 365 \\
$6^{\text {th }}$ week Videos & $139(38.8 \%)$ & $145(40.5 \%)$ & $80(22.3 \%)$ & 358 \\
$7^{\text {th }}$ week Videos & $145(40.8 \%)$ & $142(40.0 \%)$ & $78(22.0 \%)$ & 355 \\
$8^{\text {th }}$ week Videos & $149(42.5 \%)$ & $138(39.3 \%)$ & $75(21.4 \%)$ & 351 \\
$9^{\text {th }}$ week Videos & $151(45.1 \%)$ & $120(35.8 \%)$ & $70(20.9 \%)$ & 335 \\
$10^{\text {th }}$ week Videos & $153(46.9 \%)$ & $108(33.1 \%)$ & $68(20.9 \%)$ & 326 \\
$11^{\text {th }}$ week Videos & $160(50.2 \%)$ & $98(30.7 \%)$ & $63(19.7 \%)$ & 319 \\
$12^{\text {th }}$ week Videos & $167(54.8 \%)$ & $80(26.2 \%)$ & $58(19.0 \%)$ & 305 \\
\hline
\end{tabular}

Table 1 shows the number of the praises, criticism and suggestions which were sent to the students. It can be seen that the number of praises were gradually increased by $23.8 \%$ from the first videos to the final videos. To the first videos, 387 comments were given; among them, praises took account for $31 \%$. The number was bigger and bigger after videos and reached the top at $54.8 \%$ for the $12^{\text {th }}$ videos.

On the other hand, the teachers provided less criticisms and suggestions after the videos. First, the number of criticisms was considerably decreased by $17 \%$ from $43.9 \%$ in the $2^{\text {nd }}$ videos to $26.2 \%$ in the final ones. After the $2^{\text {nd }}$ videos, the proportion of dissatisfaction was gradually decreased. Second, more suggestions were provided in the first videos than in the last videos. For the $1^{\text {st }}$ videos, nearly one-third of the comments were suggestions, then the number of suggestions was given less frequently until it reached the bottom at $19 \%$.

From the statistics above, it can be inferred that the students' speaking ability was considerably improved after the videos. The students' good points and weak points in the videos were carefully shown in order that the students were deeply aware of their mistakes. Moreover, the students could follow the sources and guides that the teachers provided in the feedback, and then the students could correct their mistakes. In other words, the feedback shows its value in improving students' speaking skill.

After the course, all students were invited to do a survey in which the teacher would like to collect the participants' points of view about some aspects including the regularity, level of details, privacy and the friendliness of the feedback. The table 2 shows the participants' answers to the raised questions. 
Table 2 illustrates the answer to the first six questions. Readers can see that the students appreciate the benefits which the feedback posted on Google Classroom brought them. All participants agreed that they received weekly feedback regularly. They received more feedback than they had in face-to-face meetings.

Table 2. Benefits of the feedback from the students' perspective

\begin{tabular}{lccccc}
\hline \multirow{2}{*}{$\begin{array}{c}\text { The feedback } \\
\text { is ... }\end{array}$} & \multicolumn{4}{c}{ Number of responses } \\
\cline { 2 - 6 } & Strongly agree & Agree & Neutral & Disagree & Strongly Disagree \\
\hline Regular & $60(100 \%)$ & $0(0 \%)$ & $0(0 \%)$ & $0(0 \%)$ & $0(0 \%)$ \\
\hline Detailed & $52(86.7 \%)$ & $5(8.3 \%)$ & $3(5 \%)$ & $0(0 \%)$ & $0(0 \%)$ \\
\hline Private & $45(75.0 \%)$ & $5(8.3 \%)$ & $5(8.3 \%)$ & $4(6.7 \%)$ & $1(1.7 \%)$ \\
\hline Easy to find & $53(88.3 \%)$ & $2(3.3 \%)$ & $4(6.7 \%)$ & $1(1.7 \%)$ & $0(0 \%)$ \\
\hline Reviewable & $50(83.3 \%)$ & $7(11.7 \%)$ & $3(5 \%)$ & $0(0 \%)$ & $0(0 \%)$ \\
\hline
\end{tabular}

A number of $95 \%$ of participants responded that the feedback was detailed enough. It is known that the teachers gave feedback on all categories performed in the rating scale. Additionally, the feedback on the platform overweighed the oral feedback in which due to the limitation of time, the teachers could not show them all of their mistakes and could not show them some recommendations to eraser the errors; the teachers could not ask the students to repeat the conversations in the face-to-face lessons, too. Therefore, the participants could find the feedback on Google Classroom easy to follow, understandable and detailed enough.

Above $83 \%$ of the students showed that they loved the privacy and the ability of reading the feedback again and again. Firstly, except excellent students who would like to learn from other's mistakes, most of the students were not willing to show their mistakes and marks to others; the private feedback helped them to get more confidence than the public ones. Secondly, the students admitted that if they were sent oral feedback, they might not master all details in the teacher's comments due to the limitation of their listening skill. Moreover, after the lesson, they might forget the comments. However, thanks to the written feedback on Google Classroom, they could read the feedback some times until they could deeply understand their problems and knew what to do to avoid the errors.

Also, 92\% of the participants showed that they found it easy to access the teachers' comments. They explained that they always spent a plenty of time finding the teachers' comments on other social networks which had been used to manage their homework because the feedback was hidden or taken over by the newest comments. This action took them a lot of time. Nonetheless, on Google Classroom, videos of weeks were put in twelve separate folders; hence, they only needed to access the folders and their videos, they could find the teachers' comments immediately.

For the $6^{\text {th }}$ questions, all students agreed that they really appreciated the feedback on Google Classroom because of the benefits which the feedback and the format brought them.

For the last question, about $46.6 \%$ of the participants hoped that the feedback should be given with lower density. They meant that although they loved the regular feedback, they found quite stressed when they were asked to make speaking videos every single week. They recommended one video every two weeks.

\section{Conclusion}

To sum up, feedback is extremely essential to students because feedback helps students aware of their mistakes and how to correct the mistakes so that students may not make the same errors in the following videos. As a result, their speaking performances were remarkably improved. 
The feedback on Google Classroom improves the joy for their learning because the platform provides students some confidence to speak. Moreover, the platform can limit the time spent on finding the teacher's comments, but increase the level of understanding their speaking ability thanks to the reviewable feedback.

However, giving feedback on Google Classroom may bring some tension to both students and teachers. Students may find making videos so frequently really time - consuming. While teachers also have to spend a big amount of time on typing the feedback to all students compared with giving feedback for some students directly in classroom. To solve the issues, it is recommended an online feedback every a fortnight.

\section{REFERENCES}

[1] R. J. M. Ventayen, K. L. A. Estira, M. J. D. Guzman, C. M. Cabaluna, and N. N. Espinosa, "Usability Evaluation of Google Classroom: Basis for the Adaptation of GSuite E-Learning Platform," Asia Pacific Journal of Education, Arts and Sciences, vol. 5, no.1, pp. 47-51, January 2018. [Online]. Available: http://uruae.org/siteadmin/upload/DIRH0917218.pdf. [Accessed September 28, 2020].

[2] I. N. M Shaharanee, J. M. Jamil, and S. S. M. Rodzid, "Google classroom as a tool for active learning," AIP Conference Proceedings, vol. 1761, no. 1, pp. 0200691 - 0200696, August, 2016. [Online]. Available: https://doi.org/10.1063/1.4960909. [Accessed September 29, 2020].

[3] J. Maybin, N. Mercer, and B. Stierer, "Scaffolding: Learning in the classroom," in Thinking Voices: The Work of the National Oracy Project, K. Norman, Ed. London: Hodder Arnold H\&S, 1992, p. 186.

[4] J. Holmes, "Doubt and certainty in ESL textbooks," Applied Linguistics, vol. 91, pp. 20 - 44, 1988.

[5] B. Susan. How to give effective feedback to your students. ASCD, 2003.

[6] F. Hylanda, and K. Hylandb, "Praise and criticism in written feedback," Journal of Second Language Writing, vol. 10, pp. 185 - 212, August 2001. [Online]. Available: https://doi.org/10.1016/S10603743(01)00038-8. [Accessed January 15, 2021]

[7] D. Hybel, Understanding speaking interaction. New York: Cambridge University Press, 2001.

[8] K. Hyland, Disciplinary discourses: Social interactions in academic writing. London: Longman, 2000.

[9] F. D. F. Davis, "Perceived usefulness, perceived ease of use, and user acceptance of information technology," MIS Quarterly, vol. 13, no. 3, pp. 319-340, September 1989. [Online]. Available: https://doi.org/10.2307/249008. [Accessed September 10, 2020]. 